\title{
Potential for confliction in COVID-induced discourse in terms of training staff for law enforcement agencies
}

\author{
Lada Olegovna Ovchinnikova* \\ Kaliningrad Naval Academy - Branch of Military Training and Research Centre, Kaliningrad, Russia
}

\begin{abstract}
The purpose of this article is to construct a worldview model for a group of individuals prone to conflictive speech behaviour. This model can help law enforcement officers, including those still in training, to build an optimal communication strategy, even in unfavourable conditions. The material of the study is based on the comments in social media in respect of regional news items (TASS and Vesti-Kaliningrad press agencies). The relevant effective information engendered verbal reactions that proved to be most demonstrative for consideration and modelling. The article considers such aspects as various cognitive distortions inherent in individuals of a social medium at periods of maximum uncertainty; destructive speech strategies, manipulative strategies and manifestations of hostile rhetoric. A number of elements of the conspiratorial worldview, representing a constitutive role within the discourse in question, were considered and described.
\end{abstract}

Keywords: social media, COVID-induced discourse, conspiratorial worldview, hostile rhetoric

\section{Introduction}

The communicative situation, in the course of interaction between people and representatives of law enforcement agencies, often takes a course preventing the achievement of mutual understanding; this is explained by reasons other than lack of the officers' professionalism. The reasons for communication failure may lie in the specifics of today's information overload.

Communication may become particularly difficult and strained if the subject matter of the discussion gives rise to conflicting interpretation and assessment. Such issues include the latest requirements and recommendations of the Russian Federal State Agency for Health and Consumer Rights (Rospotrebnadzor), connected with the epidemiological situation.

The analysis of publications and comments in social media shows that, as the researchers note, "the discourse of the pandemic period may be viewed as unique and unprecedented" [1]. The specificity of the discourse is accounted for both by the particular axiological significance of the subject (the basic values "health", "safety" and "freedom" form the core of the given discourse) and by the complexity of the processes underlying it.

*Corresponding author: hairete@list.ru 
Particularly noteworthy is the fact that law enforcement officers function in their own information domain, which also creates communicative barriers. The law enforcers' information field is extending through a large number of official documents, explanations, etc. This information is either inaccessible to the population at large or is obtained by people only on a limited scale, being further mythologised or significantly misrepresented. Thus, the worldview of the population and that of the law enforcers can be radically different.

\section{Results}

Understanding the laws of formation of the information field as well as the patterns of its change, the peculiarities and strategies of its representation in speech will be much useful for the officers of the Russian Federal State Agency for Health and Consumer Rights, the Federal National Guard Troops Service, the Federal Customs Service, the Ministry of Emergency Situations or the Ministry of the Interior, enabling them, in particular, to effectively communicate the need for certain actions or restrictions to people. Effective communication requires of law enforcement officers, among other things, to face and be prepared for "aggressive rhetoric", in particular, the most commonly used methods: insult, accusation and causticity [2].

To master such comprehension, one needs an experience of prompt "sensing" of common people's information worldview and its overall analysis, in order to achieve due positioning. Social media texts, with their specific atmosphere of emotional discussion of problems and commonly practiced manipulation strategies, can provide a material for this analysis [3].

This competence can be successfully developed through the study of various humanities (Russian language and standard of speech, cultural studies, sociology, basics of business communication, etc.).

The following form of work seems to be effective: general illustrated overview of the basic factual attitudes of the population, as conveyed to the learners: cognitive, axiological, manipulative. The resulting model of the world is supplemented and concretised in the process of collective discussion (observation, analysis, brainstorming, project work, etc. depending on the organisation of the educational process). The discourse of social media comments may work as a representative material for analysis and modelling of the world vision - as a reflex of quick, emotional and system-level reaction of the collective identity to what is happening [4-6].

\section{Discussion}

The picture of the world shaped by the social media discourse in the environment of the epidemiological situation demonstrates the importance of the objective faced by law enforcement representatives in their contacts with individuals: achieving mutual understanding; ideally - eliminating the consequences of cognitive misrepresentation.

In their practice, the law enforcers face a reflex that mirrors one of such cognitive distortions - in response to a request or demand to comply with the introduced measures of counter spreading the infection (use of personal protective equipment, observance of social distance); this distortion can be termed as "claiming for arguments". It can be expressed by the following phrases: "I don't believe in COVID", "Coronavirus does not exist", "Has anyone actually seen people ill with COVID?", "Show me the red zone", "None of my folks and friends have fallen ill with it, so I don't believe", etc. The distortion lies in the fact that any factual evidence is rejected, speculatively or emotionally, with the following normally used means of representation: 
"One can write anything he wants", "Statistics always lies", "Who believes in statistics nowadays?!", "You can fake any data", "I don't believe a word of it", "Stop telling tall tales", "Stop taking people for fools", etc.

As seen from the above examples, in order to "exclude the unwanted object from the field of attention", as a representation of cognitive distortion, a combination of denial of the fact is typically used, followed by hostile rhetoric expressed by characteristic phraseological units (to fake data, to tell tall tales, to take people for fools, to whip up figures, to overstate figures, to tune the data, etc.). The manifestations of aggressive rhetoric, in this case, may be regarded as expected. Indeed, it "penetrates all spheres of human life and is inevitably reflected in media texts" [7].

A similar pattern can be viewed in the tendency to underestimate the danger, which is represented by the following statements: "Then count the tuberculosis victims", "People die from flu too", "Most people bear it without problems", "People die in fact not from the virus as such, but from comorbid diseases", etc. We can see that these statements are based on two logical premises: "Various hazards have always existed, nothing has changed" and "The new hazard is exaggerated".

The refusal to accept the reality of danger along with disagreement with the generally practiced means of prevention and protection is also expressed through a verbal strategy of devaluing the consequences of infection, even the most negative and fatal ones: grave illness, human death. In this aspect, the mechanism of recurrent dialogue between those who accepted the reality of danger and those who reject it is of particular interest.

This dialogue can be represented in general terms as two invariant repeating replicas of notional communicants $\mathrm{A}$ and $\mathrm{B}$.

A: You can talk (reason, write, speak...) this way until you face it yourself, or until your family, relatives, friends, your loved ones are affected...

B: People have always become sick and died, this is life! (This has to be accepted. / This is how it goes. / So what now, the life is over? / Then let's stay at home forever. / You can't lock everyone up.)

The recurrence and insignificant variability of this dialogue can be explained by the strong emotional background of such communicative acts. This background arises as a result of the collision of contrasting intense intentions: reflection of distressing personal experience against avoidance of such reflection, conscious rejection or inability to empathise.

A demonstrative example of "negative empathy" is a verbal strategy of devaluation. Within the framework of this strategy, the grave consequences of the disease, even lethal ones, are viewed as inevitable, so their significance for the relevant worldview is in fact nullified. This fragment of the axiological system is explicated through statements of the following series:

"Only elderly people fall ill", "All those who died had grave diseases, so they would have died anyway", "Only people with chronic diseases are in the death statistics", "He / she / they had diabetes anyway", "They have already outlived their life time", "Well, he / she has lived a good life". The speaker's main message is recognition of the inevitability of death; however, the recipient, in decoding the message, perceives it as a shift of the accent to another semantic field, namely indifference to other people's suffering, disregard for lives of elderly and chronically ill people, lack of sensitivity. Such perception is explicated in the nomination of resentment, bewilderment and indignation. The frequent phrases are: "How can you say that?!", “Aren’t you ashamed?!”, “Are you human at all?!”, etc. Such dialogues tend to be regularly repeated, and this tendency is partly due to the phenomenon of trolling which can be defined as "a communicative game that aims to involve the addressee in a communicative conflict" [6].

A less acute reaction from recipients is caused by the realisation of the speech strategy of fatalism since this strategy may contain an element of sympathy. In addition, the 
characteristic means of expressing this strategy simultaneously convey the idea of equality in the face of the universal disaster. "All of us will get through it", "All of us will die one day", "We're all headed that way", "All of us will get affected anyway", "Whoever is destined to burn will not drown", "There's no escaping one's fate". Such examples of speech behaviour are equally characteristic of those who observe the measures to prevent coronavirus infection and those who stubbornly reject them.

The strategy of "partial criticism", based on the idea of wrong actions or wrong choice on the part of superior managers, law enforcers, health workers and others - has quite a high potential for confliction. Protective measures are declared specious ("Masks are unsalutary", "Wearing masks leads to fatal diseases", "Wearing masks is dangerous", "Wearing gloves and masks is useless"); the same applies to imposed restrictions ("This is by far useless", "This was not introduced in other countries, while the statistics is the same", "This means economic death", "Treatment should not be worse than the disease"), as well as to the used treatment methods ("Medicine fails", "The right medical treatment makes the situation not scary", "They just treat people the wrong way").

In addition to the criticism as such, the statements in line with this strategy may contain alternative recommendations and action plans that have a common imperative explicated by statements from the following series: "Use your head", "Have a mind of your own", "Take responsibility for the life and health of your loved ones", "Your head needs to be right", "Turn your brain", "Seek information bit by bit", etc.

These statements may be classified as multifunctional, since they are used not only within the framework of the criticism strategy, but also as part of the protest strategy. At the same time, the protest strategy is naturally explicated by emotionally loaded evaluative statements referring to isolation, refutation and total rejection. "This is my / our personal business", "This is my choice", "You have no right!", "This is violence against a person". Accusatory speech behaviour involving sarcasm and various acts of hostile rhetoric is also typical.

"You will not intimidate everyone", "They enjoy their power", "They have fallen greedily on power", "They will chalk it up to COVID", "COVID will be their moot excuse" - these and synonymous statements are addressed either to representatives of authorities or to law enforcement officials. As a rule, these speech acts are aimed at expressing a strong negative assessment of the addressee or the object of the statement [8].

It is especially difficult to find common ground when COVID-induced discourse strategies are fitted into a conspiracy discourse. This information space is characterised by themes of denunciation, sensation, exposure and access to classified information [9]. The relevant microtexts tend to induce a specific spirit of anxiety combined with hope. Categorical imperatives are typical: calls to "wake up", "open one's eyes", "not to hide from the truth", "fight for one's life / freedom / health". The type of conspiracy theory (antivaccination movement, adherents of the "Big Pharma conspiracy", "secret government conspiracy", etc.) is not so important for these strategies. The mythologeme of the common secret enemy is organically included in the epidemiological narrative and is explicated quite regularly, including through hostile rhetoric. The conspiratorial picture of the world, quite stable in its mythological core and, at the same time, constantly updated by the latest ideological trends and news events [10-12], is a potentially dangerous ground in terms of conflict-prone development of related social contacts, including contacts of individuals with representatives of law enforcement bodies.

\section{Conclusion}

Comments in social media, being a kind of model of societal response to newsbreaks and reflecting value attitudes, fragments of the worldview, including those of conspiratorial nature, may provide law enforcers with material enabling them to predict possible conflict 
situations and to explain the reasons for hostile rhetoric that forms the "speaker's controlling stance" [13].

The situation of the rapid transformation of the social interaction system, on the one hand, provides prerequisites for unprecedented solidarity of the population, and, on the other hand, - for exacerbation of existing conflicts and emergence of new ones [14, 15; 16, p. 93].

Comprehending the mechanisms of people's complex verbal interaction in the process of interpretation of the extraordinary situation, including destructive irrational mechanisms, a specialist can prevent a conflict or mitigate its development.

\section{References}

1. S.V. Ionova, Ch. Kankan, Rus. Language Abr. 4, 36-37 (2020)

2. L.R. Komalova, Iss. of Psycholing. 4(30), 103-115 (2016). https://doi.org/ ilingran.ru/library/voprosy/30.pdf

3. A. Nuriymon, Bul. Soc.-Ec. and Human. Research 7(9) (2020)

4. V.A. Shcherbakova, Communicology: Electr. Sc. J. 3 (2018)

5. T.V. Markova, D.A. Scherbatykh, Interactive Sc. 4(26) (2018)

6. T.A. Vorontsova, Bul. Udmurt Univ. Ser. History and Philol. 26(2), 109-116 (2016).

7. A.A. Biyumena, Rus. Stud. 18(2), 164-180 (2020)

8. T.S. Gabdrafikova, Philolog. Sc. Iss. Theory and Pract. 12(3), 496-499 (2018). https://doi.org/10.30853/filnauki.2018-12-3.16

9. A.M. Prilutsky, Bul. STOUH. Ser. 1: Theology. Philosophy 82, 94-107 (2019)

10. T.N. Amiryan, Top. Iss. History, Philol. and Cult. 1(35), 311-322 (2012)

11. V.M. Rozin, Philos. Thought 5, 14-22 (2020). https://doi.org/10.25136/24098728.2020.5.32865

12. V.M. Rozin, Bul. MSUCA 1(69), 65-72 (2016)

13. T.V. Larionova, Philolog. Sc. Iss. of Theory and Pract. 7(1), 117-120 (2017)

14. T.V. Semina, A.A. Tyrtyshny, Edu. and Law 7, 11-20 (2020)

15. O.V. Yarmak, E.M. Panova, A.G. Maranchak, Z.S. Savina, Univ. News. North Caucasian Reg. Ser.: Soc. Sc. 3, 27-35 (2020). https://doi.org/10.18522/2687-07702020-3-27-35

16. A.E. Voyskunsky, Bul. Moscow Univ. Ser. 14. Psychol. 2, 90-104 (2014) 